\title{
Investigating Contemplative Practice in Creative Writing and Education Classes: A Play (of Practice and Theory) in Three Acts
}

\author{
Maureen Hall \\ University of Massachusetts Dartmouth \\ North Dartmouth, Massachusetts, USA \\ mhall@umassd.edu \\ Olivia Archibald \\ Saint Martin's University \\ Lacey, Washington, USA \\ oarchibald@stmartin.edu
}

\section{Act 1: The Beginnings}

\section{Scene One, The Meeting}

Creation comes from an impulse and an urge. November 2006, Washington D.C., ISSOTL pre-conference Carnegie Leadership Program meeting. I sit at one end of a long table in the Washington Hilton Hotel, facing a window that reveals the dome of the nation's capitol. Patti Owen-Smith leads a meeting of the Cognitive Affective Learning (CAL) Group. We talk definitions, action plans, meeting dates. At the other end sits Maureen Hall. She and I have never met until this meeting. But we slowly connect with each other as the day progresses, a connection developed through an imperceptible filament across the long table as each of us occasionally contributes to the group's discussion. Later when we discuss this connection, she will recall my comments on feminist theory at the meeting. I will remember Maureen's reference to Mary Rose O'Reilley, a writer significant to both of us.

Creation comes from an impulse and an urge. The following morning, Washington Hyatt restaurant. Maureen has a midday plane to catch, so we meet early. We talk hours, long after we're done with our breakfasts, our conversations taking long, meandering paths that detail our pasts, our families, our passions. Sometimes we just blabber, sometimes our words are more, but always they seem to cement a common need to blend our contemplative practices (which could be called a wonderful Buddhist-Transcendental-Existential with a trace of Baptist-tossed-in broth), with our professional lives as faculty. At some point, a conversational path ends with a collaborative project. Through our membership in the Carnegie Leadership Program, we knew we would be connected for the next three years. It made sense to use this already established connection and develop a project that grew out of our common interests in teaching and learning. Our idea was to investigate how using reflective writing as contemplative practice affected our students' sense of who they are as writers and as teachers of writing. We were also interested in finding out if writing at the beginning of each class affected our students' perspectives on their value of reflective writing as a tool for learning. Using Maureen's graduate level methods of teaching writing course and my undergraduate creative writing course, we planned to integrate contemplative practice into our pedagogy via 2-4 common writing assignments which would be appropriate for both courses. 
Later, Maureen will quote Pat Hutchings in an email to me: "Teaching, like any craft or art, advances when people find like-minded colleagues to work with, review their efforts, and push them to the next stages of thinking." (Personal communication with Pat Hutchings, October 30, 2007)

Creation comes from an impulse and an urge, according to the ancient BuddhistAsian monkey stories (Lockwood, 2007).

Scene Two, Back home at our respective universities.

Contextual considerations of the Whys and Hows of Collaboration, Cognitive-Affective Learning, and Contemplative Practices.

Maureen's research:

In terms of our collaborative Scholarship of Teaching and Learning (SoTL) project, Olivia and I have attempted to create a communal space for teaching and learning between and among ourselves and our students. Through the creation of two common writing assignments called "Writing from the Inside" and "Writing from the Outside," (see appendices for assignments), we investigated the role of contemplative practice in teaching and learning via reflective writing. Students at both universities participated in identical prompts, evaluated their experiences with these assignments and shared their evaluations across campuses through e-mail.

Using Krathwohl's (1964) Taxonomy of Affective Domain as an assessment instrument, we evaluated student responses to describe the ways in which the practice of reflective writing in the classroom informed students' values of the need for reflection and reflective writing within the classroom and within their lives. Because of the disciplinary content of our particular courses, we were also interested in exploring how reflective writing informed students' identities as writers and as teachers of writing - that is, how are their values about these understandings of Self informed as a result of this practice? The secondary purposes of the project were to study the effectiveness of collaborative practice in cognitive affective learning (CAL) and model the changing nature of faculty work in higher education.

If we begin to understand the complexity and demands of the teaching profession, and use this understanding to improve teaching and learning, we need to, as Shulman (2004) points out, we need to be open to new and transformative forms of pedagogy. Contemplative practices as a part of contemplative pedagogy represents one form of unconventional pedagogy. Olivia and I agree with Shulman's definition of contemplative practice, with its emphases on the student's physical, mental, and social components, coupled with a Buddhist-like focus on the present:

Contemplative practice in education refers to a range of activities which emphasizes a grounding and habitation in the present moment. Any kind of contemplative practice attempts to integrate all aspects of cognitive and affective learning because that is the way that learners respond and come to understand concepts, ideas, and experiences. Contemplative practice regards the learning process holistically. Naturally, the learning process encompasses both thoughts and feelings. A contemplative pedagogy attempts to quiet the chaos and distractions inherent in a modern life in the name of the best teaching and learning.

When we focus within our classrooms on contemplative practices, we attempt to develop a teaching and learning space that allows sustained reflection and focused mindfulness in the learning process. Such a focus allows a conscious effort to 
integrate physical and mental health within the curriculum. When we incorporate contemplative practices within the classroom, we acknowledge that the stress and overstimulation of the $21^{\text {st }}$ century needs to be mediated to "quiet the chaos" in order to help learning take place. Such practices can "help to shape not only how the teacher interacts with students but also how students interact with each other" (Hill, 2006, p. 1724).

When we focus within our classrooms on contemplative practices, we are also enacting within our teaching the importance of affective learning. Affective learning is involved in both feeling safe and feeling connected, and meaning-making happens more readily when attention is given to the affective parts of learning (Wiggins \& McTighe, 2001; Tomlinson 2001). One essential element of any learning environment involves how students and teachers feel about their mutually created space; this is the affective domain. Emotions are a vital part of the affective, and, empathy as an emotion, informs the connection between cognitive and affective learning. Our openness to our own emotions dictates the degree to which we will be effective in reading the emotions of others. (Goleman, 1995; Hall 2005). Gaping holes exist in a teaching and learning space without some focus on how teachers and students feel about learning. This is not to say that it only matters how teachers and students "feel" about learning; teachers must intentionally focus on ways to weave together both the affective and cognitive dimensions for the best learning.

\section{Contemplative Practice and Its Relation to Community}

The creation of community is a bridge between cognitive and affective learning (Hall, 2005). In many ways it can provide solutions to the problem of how to develop a safe and connected classroom. Yet creating a community in any teaching and learning environment, whether it be in $\mathrm{K}-12$ or higher education setting, is not a foregone conclusion. Arthur Zajonc (2006) illuminates some aspects of community, "Healthy relationships do not happen automatically; each of us must cultivate them intentionally" ( $p .1744)$ Contemplative practice, used with the intention of improving learning, offers one such conduit for the creation of a community of learners. Contemplative practice offers a route to create community with learners and helps to define roles in the learning process:

It is mining the resources that are present in learners, cultivating intimacy with them, and allowing them to engage in their own learning, as opposed to having the arrogance of thinking we are the ones that make them learn. (Kabat-Zinn, 2005).

Likewise and in the bigger picture, the work of the Scholarship of Teaching and Learning (SoTL) involves a community of scholars working together, not in isolation. Although Olivia and I have attempted to create a communal space for teaching and learning between and among ourselves and our students, the larger community of scholars is important as well; there is a discourse involved. We are modeling the changing nature of faculty work. Though I may not have any direct contact with other SoTL researchers, my task as a part of the larger community of scholars is to be able to read, understand, and add to the work of others. In The Wisdom of Practice (2004), Shulman reflects on the importance of community in scholarship and the notion of scholarship as community property:

To engage in the process of inquiry, to become a scholar of and in education, is not only to take on the mantle of method and the rigor of the discipline. It entails becoming an active member of a community of scholars and a community of educators. We must pursue and 
publish our research in ways that reflect the moral obligations of community membership. These obligations are entailed when we

recognize that this is a community whose members are interdependent; each of us depends on the trust that we can place in the work of other members of the community, because an intellectual and scholarly community rests on the assumption that its members can build on each other's work. We offer our findings, our new knowledge, to one another as community property. (p. 304)

A community, after all and by definition, is where people come to count on others. The closer the collaboration, the more we are vulnerable to one another. The changing nature of faculty work, especially in terms of utilizing contemplative practice, requires collegial actions where two or more faculty members create a safe space between them in the name of improving teaching and learning. This is the same work that K-12 teachers need to engage in for better teaching and learning. I like to think of these spaces as having an oxymoronic quality to them-safe vulnerability. These "spaces" between and among teachers do not happen automatically. They come about through intention.

\section{Scene 3: East Coast. West Coast. And Somewhere in Cyberspace. Drs. Hall and Archibald Create Communities}

Creation comes from an impulse and an urge. (Lockwood, 2007) Spaces for community also come about through such intentions. But how can faculty and students create a community of teaching and learning when campuses span a distance of 3,000 miles? As we collaboratively developed, enacted, and evaluated this project, we were also evidencing the shifting characteristics of faculty work in higher education.

In order to add to the conversation about this changing nature of faculty work, we recognized teachers as learners and learners as teachers. Good teaching and learning practices are good for teachers and students alike. Shulman (2004) provides worthy rationale for reform:

Changes are needed in classrooms to render them more powerful environments for student learning, and similar changes are needed in classrooms and schools to make them suitable settings for teacher learning. Teacher collegiality and collaboration are not important merely for the improvement of morale and teacher satisfaction...; they are absolutely necessary if teaching is to be of the highest order and thus compatible with the standards of excellence demanded by the recent reforms. Collegiality and collaboration are also needed to ensure that teachers benefit their experiences and continue to grow during their careers." (p. 11)

Enter contemplative practice as a conduit for teachers (whether they be in higher education or $\mathrm{K}-12$ ) to reflect on their experiences and chart directions for their own development as practitioners.

\section{Modeling the Changing Nature of Faculty Work}

Our collaboration was not easy; it involved a commitment of time and energy outside our normal teaching load. Two weeks after the November 2006 conference, we began a series of e-mail interactions, scheduled phone calls, and mailings to develop our project from one coast to the other. These communications reveal a process that 
focused on setting goals, establishing definitions, creating common assignments, and considering ways of assessing learning. They depict two colleagues attempting to plan a project long distance and finding ways to connect while living very busy lives. Emails throughout these months evidence daily conversations for a short period, followed by large gaps in time until one of us will draw the other back into the project with a personal question. They often have as a subject heading a message like "In my office today at 1, let's talk," and depict efforts, sometimes in vain, to circumvent a 3-hour Eastern-Pacific time zone difference.

Many emails focus as much on our achievements and difficulties in our personal lives (typically rendered as parentheticals) as the plans and practices of our collaborative project. They evidence our attempts to rationalize the project and reveal bits of our personal lives, hobbies, and relationships as our collaboration develops. We write about our two dogs, Ozzie and Hrothgar. We write about Maureen's polo playing and Olivia's habit of "verbing her nouns." They reveal two women working on a project while seeking grace and courage to face the turmoil of their personal lives as Ozzie dies, Maureen breaks her leg, Olivia's mother breaks a hip, and two of Maureen's horses are put down. They provide real-life answers to the rhetorical question O'Reilley (2006) asks educators:

Why is contemplative practice needed in our culture? We live hectic lives and need time to process information and construct new knowledge by connecting lived experiences to new information. Our work is in the context of teaching lives; we are all students and teachers. (O'Reilley, 2006)

Creation can come from an impulse to connect and the urge to make meaning out of daily chaos.

Throughout the project, our initial objectives of building on practices in CognitiveAffective Learning (CAL), creating contemplative practices to promote affective development, and exemplifying the changing nature of faculty work remained constant. As main contact leaders of the Carnegie CAL Leadership Program at our respective institutions, we deliberately developed a project with the hope that it would infuse the scholarship of teaching and learning (SoTL) more fully into institutional culture within our universities. We were interested in applying many of the aspirations our CAL cluster group had developed at the November 2006 meeting in Washington, D.C., including developing practices underpinned by inter-institutional collaboration and endeavors that evidence how SoTL contributes to other important agendas, such as the non-traditional pedagogical approach of contemplative practice.

Although we represented different disciplines, we both shared "a few deep aims as teachers that, curiously, have little to do with disciplines as such" (Gregory, 2004, p.2). We discovered early on in our collaboration that the learning outcomes which served as core for our teaching were, as with Gregory's findings on ethical teaching and learning, identical in many ways. We wanted, for example, our students to become more open-minded, introspective, creative, curious, critical, and sensitive to other people. And we passionately agreed with Harold Roth's (2006) assessment of the current state of teaching and learning:

At the dawn of the $21^{\text {st }}$ century, we find ourselves at a crossroads. Our scientific knowledge of how the world works has never been stronger, but our ability to use it to transform our lives to greater personal and social harmony remains relatively weak. We can use our technology of the outer world to treat previously incurable diseases, 
but our mastery of the "technology of the inner world" is so rudimentary that we can barely contain the passions that lead us to destroy the very human life that we, paradoxically, struggle so hard

to preserve. (Roth, 2006, p. 1787)

Our challenge was to use contemplative practice as a way to enhance learning and mindfulness in order to transform lives, while all along, secretly hoping we could save the world...lofty goals? And we were certainly cognizant of the potential of this project for our own personal lives. As educators such as O'Reilley (2006) and Seidel (2006) have noted, bringing "mindfulness to the moment of teaching" is good for the teacher herself. Seidel argues:

Contemplation is not a method, but rather a practice - an everyday practice that can transform the world. It is difficult work. It is about being prepared to meet life moment by moment as it arrives...This discipline of greeting each moment as it arrives seems somehow opposite to the ways we are often expected to be in schools. It locates us in a larger vision, in a more expansive and generous place-time. It is making space to remember that we are in the midst of all these many relations, always. It is trying to write a different story about what it means to be in schools in the context of what is happening globally, ecologically, politically, economically. (p. 1911)

Our contemplative work represents an intentional collaboration between two people who cultivated community with each other. We made time in our busy teaching and personal lives to develop our connection in the name of improving teaching and learning for ourselves and for our students. This work located us in the present moment and as a part of the larger vision to which Seidel refers. Contemplation also contextualizes us in the present and in the world of human and ecological relationships.

\section{Act Two: Evidence and Findings}

\section{Scene 1: Cyperspace Galore. Gathering the Evidence \& Looking for Meaning}

\section{Reflective Writing as a Means of Contemplative Practice}

Hill (2006) acknowledges the interest in contemplative practices as endeavors "to facilitate greater mindfulness in a range of academic disciplines and professional fields" (p. 1723). In many ways the efforts of our project fit the category that Hill describes: "[A] means of expanding and transforming knowledge" within our respective academic fields. Our project's emphasis on contemplative practice led us to begin to develop a series of reflective writing assignments that would bridge the diverse disciplines, students, and teaching levels of our two courses and would be used in our classrooms during the spring 2007 semester. Olivia's course, ENG 292 Creative Writing, was an undergraduate course at Saint Martin's University in Lacey, Washington, with an enrollment of 21 students. Team-taught with two other professors, the course focused on writing in the genres of creative nonfiction, plays, and short fiction. Maureen's course, EDU 612 Teaching Elementary and Middle School Writing, was a graduate-level education course at University of Massachusetts Dartmouth, with an enrollment of 16, and intended for experienced teachers seeking to hone their skills in and strategies for teaching writing in elementary and middle schools as a literacy course that counted towards the (MAT) degree. 
Contemplative practice as enacted via reflective writing has received much attention recently from educators because of its potential for introspection, deep learning, and even psychological health (see, for example, King \& Kitchener, 1994; Ross, 1990; Spalding \& Wilson, 2002). Dewey (1933) defines reflection as an "active, persistent, and careful consideration" of knowledge. This "active, persistent, and careful consideration" is implicit in Krathwohl's (1964) description of how affective learning is evidenced:

Affective learning is demonstrated by behaviors indicating attitudes of awareness, interest, attention, concern, and responsibility, ability to listen and respond in interactions with others, and ability to demonstrate those attitudinal characteristics or values which are appropriate.

Because of its focus on how we develop values in our life, we became interested in Krathwohl's Taxonomy of the Affective Domain (Figure 1.) as a way to assess student learning. Although we were aware of Shulman's Table of Learning and other affective assessments, we specifically chose Krathwohl's Affective Domain because it applied so well to our project and seemed to be underutilized in educational practice. Krathwohl's categories detail how we adopt values about objects and concepts, classifying the cumulative adoption of a value in levels of learning.

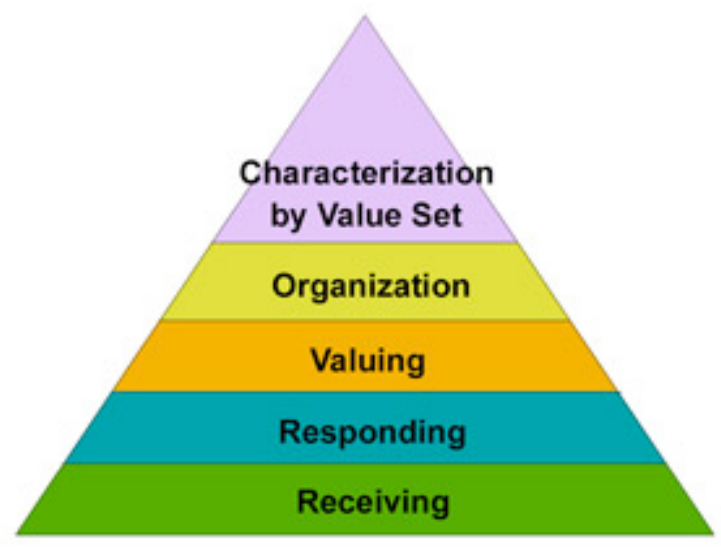

Figure 1. Krathwohl's Affective Domain|

These levels are characterized by receiving awareness of some object or concept, responding via new behaviors as a result of the awareness, formulating a value to it, integrating the value into one's life, and using it consistently (Krathwohl, Bloom, \& Masia, 1964). Using Krathwohl's Taxonomy, we wanted to explore through our project the question: How does a practice of reflective writing in the classroom inform students' value of the need for reflection and reflective writing within the classroom and within their lives? For the purpose of this project, we defined "value" as having a positive perception of the experience, not just placing a "value," whether positive or negative on the practice. Because of the particulars of our disciplines, we were also interested in exploring: How does reflective writing inform students' identities as writers (both groups) and as teachers of writing (UMass Dartmouth students only) -that is, how are their values about these understandings of Self informed as a result of this practice? 
We developed for each of our classes a series of reflective writing prompts that would be used at the beginning of each class in hopes that consistency and repetition would move students beyond just responding to the prompts, into levels of internalization/integration and commitment to reflective writing as a life practice. Initially our goal was to develop four reflective writing prompts that both groups of students would do during the semester, but, as project plans evolved, we settled on crafting two of the many reflections they wrote during the semester that would be common to both classes: "Writing from the Inside" and "Writing from the Outside." The first prompt asked students to visualize a rose changing colors in a mirror, then replace that rose with an image of themselves "as a writer." They were then asked to write about what they "saw" when they viewed themselves as a writer in the mirror, including an examination of their past writing experiences (see Appendix A). We were particularly interested in having students begin to take on identities as writers and reflect about that Sense of Self.

"Writing from the Outside" involved students first watching Ron Fricke's awardwinning documentary Baraka, a film with no dialogue, but with images about the beauty of nature and humanity contrasted with the disconnected, mechanical aspects of modern life. Students were asked to write about "an image, many images, how you feel afterwards" (see Appendix B). This second prompt, we hoped, would allow students to move beyond reflections about Self, into reflections about and empathic connections with the world around them for potential agency and activism.

The two common reflective assignments differed in terms of when students wrote about the prompts. The Saint Martin's students used the first 30 minutes of the class period for these writings, and wrote their reflections in silence, as they did with other reflective writing assignments that were assigned the first half hour of class. The University of Massachusetts Dartmouth students wrote the prompts as an assignment outside of class, Maureen's class always beginning with an open-ended 15 minute reflection with music playing in the background, while students wrote about their day, their week, their life. Maureen's group shared their reflections with their peers.

Another variable of the common reflective assignments was the difference in terms of when the assignments were given during the semester. Olivia assigned the two reflective prompts within the first weeks of the course, using the time period when she taught creative nonfiction and before her two other team members began teaching their particular genres. Maureen used the prompts as assignments later in the semester, after students had been exposed to some course content and several reflective writings.

The "Writing from the Outside" reflection differed as to how and when students from both groups saw (or did not see) the film Baraka. Maureen's students watched the first 60 minutes of the 90-minute documentary, and viewed it during class time. At Saint Martin's, Baraka was shown in its entirety just before the class began to students who could come early. The eight students who could not attend class early to view it were given during the reflective writing period a collection of images from the film and asked to write about one image or several.

After both groups had written on the two prompts, students from two universities evaluated their experiences with the two common reflections and shared their evaluations with a student from the other campus with whom they had been paired by the course professors. 
Scene 2: Emergent Findings

Throughout the spring 2007 semester, we collected data for the project from 32 students on the two campuses, 16 students from University of Massachusetts Dartmouth and 16 students from Saint Martin's University who had participated in the cross-institutional emails. Institutional Review Board procedures for the protection of human subjects were followed at both universities. Students agreed to have their voices included in this paper. Data sources included student journals,

emails from students to each other, emails sent to and from Maureen and Olivia, and other course-related materials.

Based the data, a total of 30 of the 32 students at the conclusion of the project valued a practice of reflective writing at the beginning of class. These 30 students had moved beyond Krathwohl's Level One category, receiving an "awareness" of reflective writing. They also had moved beyond Krathwohl's Level Two category since they did not just respond to the writing prompts, but, in their responses, indicated that they valued the experience, Level Three of Krathwohl's taxonomy.

A total of 14 of the students indicated that they would like to integrate reflective writing into their lives after the course was over, Level Four in Krathwohl's taxonomy. They internalized the experience to the degree that they wanted it within their lives after the course was over. What was unclear at the conclusion of the project was determining if students would use reflective writing consistently in their lives and commit to it as a life practice, Krathwohl's Level Five.

Explanations of how reflective writing affected students' identities as writers surfaced as we unpacked the data, using the lenses of emerging themes. Comments like the following student's explanation were echoed by many:

I realized from the prompts what writers go through when they write. A writer doesn't just sit down and start writing masterpieces; a writer must think deeply about what his or her intentions are - what is the aim, the goal of writing a certain piece-and a writer must also try to picture exactly what a situation or scene in their story/essay/drama will look like. A writer must look at things from a reader's perspective. ...I have developed a deeper connection $\mathrm{w} /$ other writers in my class.

The student here views reflective writing as a practice that allows him to experience aspects of writing process, including audience and reader response, along with the hard work of planning - all excellent habits of writing. Not only does he see himself as part of the large community of writers; he sees himself in a writing community with his classroom peers, increasing the likelihood of more positive experiences in peer editing group work, a significant characteristic of a successful writing classroom. For these two classes, reflective writing bolstered the possibilities of better teaching and learning of writing as students took on identities as writers.

We were also interested in exploring how reflective writing informed UMass Dartmouth students' identities as teachers of writing. Examples of such identities were most visible in the email exchanges between UMass Dartmouth students and the Saint Martin's undergraduates. In their responses to emails from SMU students' evaluations of the reflective writings, UMass Dartmouth students typically replied with advice about solving writing problems like writer's block, poor self-esteem, sharing one's writing to peers, and even, from one UMass Dartmouth student, a better way of organizing the email a SMU student sent her. For Maureen's UMass Dartmouth students, the act of exchanging emails from the two courses allowed 
them to take on roles and identities as teachers of writing, thus honing their pedagogical skills.

When we considered the question of how this practice of reflective informed the students' values for the need of reflection in the classroom, three distinct themes emerged in students' explanations of why they valued it: I) Preparing students' minds for focused work, II) Writing as therapy/ writing as transformation, and III) Sense of agency as writers, writing community and the need for interconnectedness.

\section{Preparing students' minds for focused work}

Like most people in the America of 2007, both undergraduates at SMU and graduate students at UMD live harried lives. Most of the graduate students are full-time practicing teachers and arrive for a 4:00 p.m. class after a full day of teaching; they arrive "carrying" the weight of their days. Similarly, many of the undergraduate students at SMU have part-time jobs, are involved in extracurricular activities, and typically take four-to-five courses. We discovered from student comments that the benefits of reflective writing include its possibilities of preparing students' minds for the focused work of the classroom. One student shared:

Reflective writing calms my mind. It helps me focus, and I wish all my classes started that way. I'd be a lot more productive if I was focused in all my classes.

These busy students saw reflective writing as a centering practice to clear the mind and prepare for work in class. Their comments described the reflective practice similar to the sky after a hard rain sweeps away the storm clouds, as one that "clears my thinking for the class ahead," "puts me in a good mood for learning," and "helps me to open up, saying things in a different way or just going with my instincts about an idea." One student noted:

It calms my insides. My brain is silenced, must be silenced, so I can listen to my heart. The writing prompts challenge me at the beginning of each class, forcing a sudden calm over my frantic, spastic day. It is during this time that I can actually THINK.

The reflective writing as contemplative practice at the beginning of each class created a ritual or routine that allowed a way for participants to return to the present moment. Students utilized the reflective writing at the beginning of class as one route to become present with others in the teaching and learning space. It was a way to "breathe." As one student insisted, "There are times in life when you just need to take a few moments for yourself. STOP everything and just stand still and breathe."

\section{Writing as Therapy/ Writing as Transformation}

One of the surprises for us in this project was the number of students who found the writing exercises to have therapeutic, stress-relieving effects. One student shared:

S-t-r-e-s-s is the number one contributor to inactivity because it draws me deep inside myself, like a turtle hiding from the world. To be drawn out, I must eliminate the stress...and the writing prompts accomplish this. Without this, I would still be running all through class, even though it looks like I'm sitting. The prompts also cause me to step outside of myself for a moment and look down - to see things I would not notice otherwise and to connect. What do I mean by 
connect? I mean that I can connect with a larger purpose in life.

Students described the reflective practices in ways that allowed them to "wind down from the chaos of the day," as a time that "gives me a chance to gather my thoughts and reflect on my thinking." Some students noted how reflective writing allowed them to relieve frustrations "much in the same way that talking things over with a

friend helps." Daily challenges "become more manageable." A student from the creative writing class explained the benefits in this way:

I race, I run...But Monday evenings at six o'clock, after I run up four flights of stairs to creative writing class, the racing suddenly comes to a halt. I sit at a desk with a blank paper, or screen, calming my insides. My brain is silenced, must be silenced, so I can listen to my heart. The writing prompts challenge me at the beginning of each class - forcing a sudden calm over my frantic, spastic day. It is during this time that I finally can THINK. And think I do...reflecting, pouring out my heart, the ink like black blood spilling forth. I love the sense of peace after creativity has been preformed. It is in writing and creating that I truly find myself. I feel alive and free. The pen in my hand releases my mind, my heart, from the bondage of busyness.

Writing became an outlet through which experiences could be weighed and debriefed, allowing students to move to the present moment for, what they said, was deeper listening and learning. Students had different kinds of stresses and worries, but the writing ritual was a common practice that they shared. Writing provided a mode of expression that allowed students to disconnect ("write-away") their actual problems and stresses and then re-connect with their identities as learners who could be more fully present with others in the name of learning.

\section{Sense of Agency as Writers, Building a Writing Community, and the Need for Interconnectedness \\ Students started to appreciate the community of writers surrounding them as generative. Because they were doing the work of writers, they could begin to understand what writers need. They wrote about how the reflections made them more successful in their peer writing groups. They gained confidence and were able to provide support to others because they started to see themselves as "real" writers who had something to contribute to the writing community. One student said:}

It [the reflective writings] brought sort of a zest to the class, discovering something new about myself. It forced me to look inwards, to find an expressive waterslide to play on. Expressive waterslides are much better than mere wells or founts of expressiveness. What does a well do? It just sits there. .. Same with fountains. They sit in one place burbling contentedly to themselves and you can take it or leave it. Get on a waterslide now, and you go places. The water and your mind are no longer disconnected; they're freefalling to wherever it is that the slide goes. ...the reflective writings bring me to a place where I can find my waterslides. Once I get on my waterslide, things flow a bit more smoothly. It's easier for me to see where the story should begin and end. I find a point in my nonsense and work it out. I play with concepts more, and find words easier to experiment with.

Reflective writing, as our data evidenced, helped many students connect with the larger writing community to help them better understand the writing process and 
give them "that little bit of self-esteem needed to push forward in class."

According to one student, "I learned a lot about my identity in general and how that identity relates to how I see myself as a writer." This was echoed in other student evaluations about reflective writing, as with this student's comment: "By thinking critically and writing honestly in class, I have been able to get a better picture of things and understand myself better as a writer." Another student wrote about finding himself "paying more attention to the little things around me, the way a room smells, the way the wind is blowing, even the body language of those around me."

Students described how the practice allowed them to understand themselves better, to understand, as one student said, "how I process information." Some students discussed the effects of these writings outside of class. One student depicted his experiences as:

Every so often I will find myself outside of class trying to turn a situation that I experience in my day into a story - I try to think about how to put something in my thought-process as a writer.

Students were beginning to reveal their understanding of the processes in which "real" writers go through; this understanding became somewhat internalized. As writers, they began to realize that they all shared the same struggle and that there were ways to gain sustenance from their individual visions as well as their collaborative work.

\section{Scene 3: Revelations under the Tree of Contemplative Practices and Broader Significance of Contemplative Practice}

Figure 2. The Tree of Contemplative Practices 


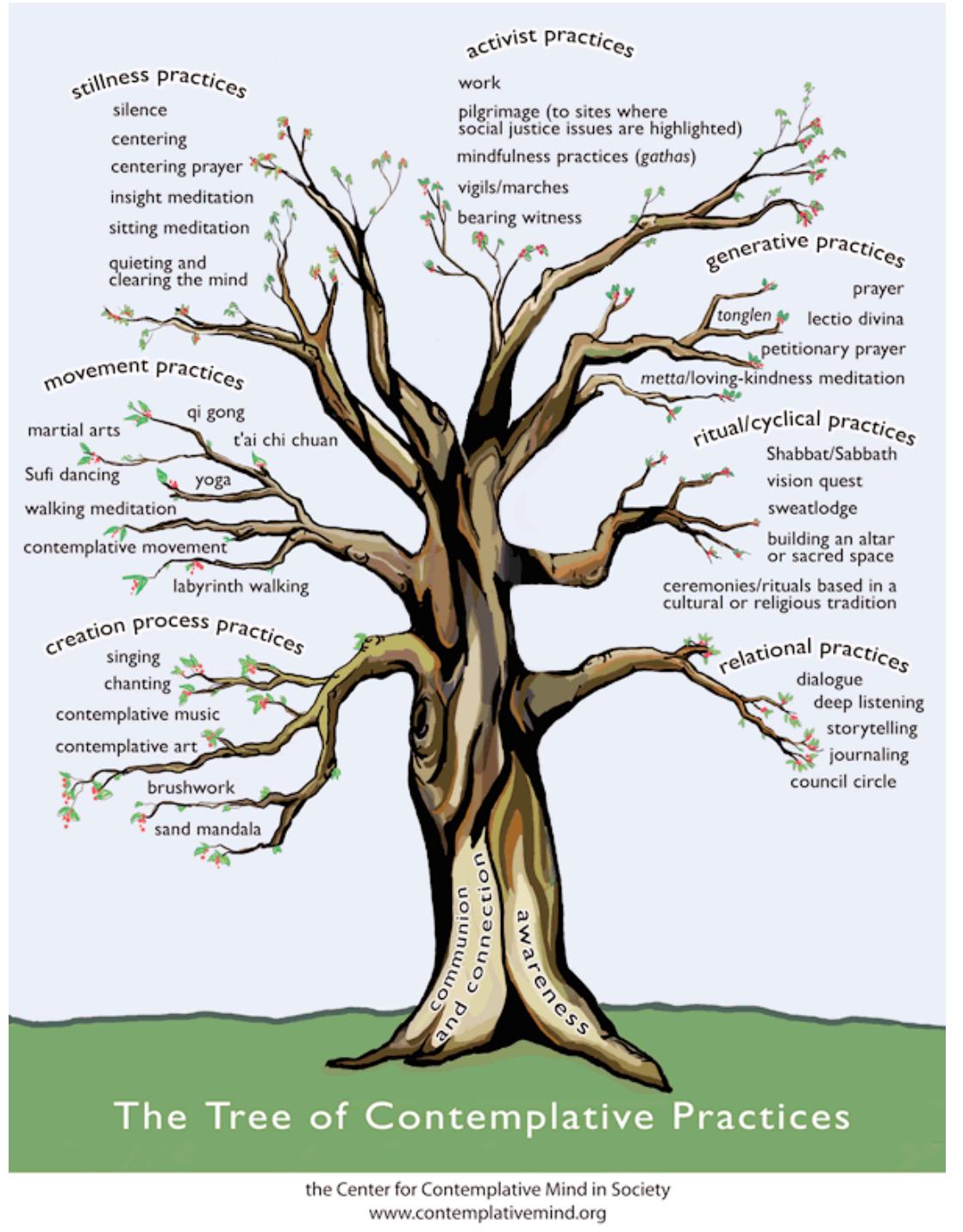

Why is contemplative practice needed in our culture? We live hectic lives and need time to process information and construct new knowledge by connecting lived experiences to new information. Our work is in the context of teaching lives; we are all students and teachers. After beginning to read student reflections about the project, we found ourselves returning several times to an image Maureen discovered early on in our planning process: The Tree of Contemplative Practices from the Center for Contemplative Mind in Society (www.contemplativemind.org), which is located in western Massachusetts (Figure 2.). The tree presents on its branches various kinds of contemplative practices, listing below each kind of particular activities. The tree presents on its branches various kinds of contemplative practices, listing below each branch particular activities that represent the particular practice.

Our project has enacted many of the tree's categories. When Olivia used silence to create space for reflective writing activities, she was enacting the stillness practices of centering and quietude. Maureen's pattern of always playing music in the classroom when students wrote reflections enacted the creation process practice that employs contemplative music to encourage creativity and centering. One reflective practice which the Saint Martin's students did involved moving around the classroom 
and reflecting on their names before writing about the experience, an example of the movement practice of walking mediation.

The ritual of repeating reflective writing at the beginning of each class represented the tree branch of ritual/cyclical practices. The project's emphasis on having students "bear witness" to the reflective experiences via email was an example of the branch of activist practices. Most of our activities in this project fit below the branch of relational practices: class dialogues, journals, storytelling, and the deep learning that several students noted in their emails to each other, all done in the "counsel circles" in our classes. Between the two of us, we carried on our own relational practices in the forms of dialogue (phone, email, face-to-face); storytelling of work and personal life, deep listening to each other's narratives, and created a "cyperspace commons" to bridge the miles and break through the boundaries that separated us. Shulman (1993) and Huber (2005) write about the solitary work of teaching; Shulman refers to it as "pedagogical solitude" - that is, teaching can be very isolating despite the fact that it might be perceived as very social and done in a community.

The Center for Contemplative Mind in Society allows a view on all things contemplative. We are working on making meaning of our work in terms of where exactly it might be located in the context of the tree. Certainly our work is a part of the roots where "communion, connection, and awareness" reach down into the earth. Our work is generative; our students created pieces of writing in connection with others in the teaching and learning space. The larger vision of this project, one that locates our work as a model for the changing nature of faculty work, highlights a new awareness of the importance of contemplative practice for all. And our "communion" represents a knitting together of the various strands: professors, teachers of writing, creative writing students. This intentional creation of community grew from an impulse and an urge.

\section{Act Three: Endings and Beginnings}

\section{Scene 1: Back Home. Drawing Conclusions}

This article reports the results of a research project involving "unconventional" pedagogical practices and examines the impact of contemplative practice on teaching and learning in an undergraduate creative writing class and a graduate level methods of teaching writing course. Using student evaluations of the projects, we can conclude that it is possible "to enhance learning through reflection and insight" (Holland. 2006, p. 1842). At the conclusion of the project, over $90 \%$ of the students' from both classes valued reflective writing as an assignment at the beginning of class, and were at least at Level Three of Krathwohl's Taxonomy of the Affective Domain. A total of $45 \%$ of the students from both classes were at Level Four in Krathwohl's Taxonomy and evidenced an interest in integrating it into their lives beyond the course.

The three themes that emerged from the data offered explanations from students' perspectives in addressing how reflective writing inform students' value of the need for reflection and reflective writing within the classroom and within their lives. Reflective writing allowed students to focus more on the work in the classroom, reduce stress from their everyday lives, and connect with the writing communities in their classrooms and in the larger realm. Students' identities as writers and as teachers of writing were enhanced, much because of the community-building outcomes that reflective writing achieved, and because of the email exchange 
between the two classes which provided practice in honing the UMass Dartmouth students' pedagogical skills.

Furthering our own work in writing creative non-fiction about teaching through fostering the creation of communities of writers in our courses makes practical sense. Our work provides a writing route to the integration of thought and feeling, which is not easy to do. There may be limits as to what we can conclude about the effectiveness of our work, but it is clear that the pace of lives we live need moments of peace and reflection. Life seems to be lived at an ever-increasing hectic pace. Reflective writing as contemplative practice provides a humane and thoughtful way for us to express ourselves in writing, and, in some ways, hopefully will even make the world a better place to inhabit.

\section{Scene 2: Going Forward}

Our lives are incredibly fast-paced journeys through time. There doesn't seem a moment to spare. We must make time to consider our interior lives. This contemplative focus does not come easily or automatically. As teachers, we can create contemplative opportunities for our students and for ourselves. Kabat-Zinn (2005) urges:

These capacities need to be uncovered, developed, and put to use. Doing so is the challenge of our life's time, that is, a chance to make the most of the moments we have. As a rule, our moments are easily missed or filled up with stuff, wanted and unwanted. But it is equally easy to realize that, in the unfolding of our lives, we actually have nothing but moments in which to live, and it is a gift to actually be present for them, and that interesting things start to happen when we are. (p. 9)

"Interesting things" also start to happen when we reconsider writing forms. This article, about an "unconventional pedagogical project," has been written in an "unconventional" form. We have deliberately subverted the typical research reporting format in an attempt to jump beyond the often limiting boundaries and templates of conventional writing forms, to create the acts of a journey - our journey - through this project.

Through our common assignments, students in both courses on the East and West coasts were given opportunities to reflect in writing and create from the stillness inside them. As Jon Kabat-Zinn explains, "While we may be highly educated, if we are without deep integration of thought and feeling, our lives are incomplete." ( $p$. ix). Kabat-Zinn writes about how the best kind of education must consider the nature of the mind. Even in our present day era, we still know remarkably little about how people learn best. There is much more to know. Projects such as this provide new modes of teaching and learning in order to find ways to deepen learning.

The impulse and urge to create move us to discover more.

\section{References}

Dewey, J. (1933). How we think: A restatement of the relation of reflective thinking to the educational process. NY: D.C. Heath and Co. 
Goleman, D. (1995). Emotional intelligence. New York: Bantam Books.

Gregory, M. (2004). Pedagogical disjunctions, or, if I say I want my students to be mainly learning $x$, why do I think mostly about teaching $y$ ? Journal of Cognitive Affective Learning. <www.jcal.emory.edu>. 1.1, 2-10. Fall.

Hall, M.P. (2005). Bridging the heart and mind: Community as a device for linking cognitive and affective learning. Journal of Cognitive Affective Learning. $<$ www.jcal.emory.edu >. Spring.

Hill, C. (2006). Introduction: Contemplative practices and education. Teachers College Record Volume 108 Number 9, 2006, p. 1723-1732.

<http://www.tcrecord.org> ID Number: 12676, Date Accessed: 10/26/2007 4:18:08 PM.

Holland, D. (2006). Contemplative education in unexpected places: Teaching mindfulness in Arkansas and Austria. Teachers College Record.

<http://www.tcrecord.org> 108.9. 1842-1861.

Huber, T.H. \& Hutchings, P. (2005). The advancement of learning: Building the teaching commons. San Francisco: Jossey-Bass.

Kabat-Zinn, J. (2005). Coming to our senses: Healing ourselves and the world through mindfulness. New York: Hyperion.

King, P.M.,\& Kitchener, K.S. (1994). Developing reflective judgment: Understanding and promoting intellectual growth and critical thinking in adolescents and adults.

San Francisco: Jossey-Bass.

Krathwohl, D. R., Bloom, B.S., and Masia, B.B. (1964). Taxonomy of educational objectives: Handbook II: Affective domain. NY: David McKay.

Lockwood, S. (2007, July). Monkey (Creation story). Story told at informal gathering in Olympia, Washington.

O'Reilley, M.R. (1998) Radical presence: Teaching as Contemplative practice. Portsmouth, NH: Heinemann.

O'Reilley, M.R. (2005) The garden at night: Burnout and breakdown in the teaching life. Portsmouth, $\mathrm{NH}$ : Heinemann.

Roth, H. (2006). Contemplative studies: Prospects for a new field. Teachers College Record. <http://www.tcrecord.org> 108.9. 1787-1815.

Ross, D.D. (1990). Programmatic structures for the preparation of reflective teachers. In R. T. Clift, W.R. Houston, \& M.C. Pugach (Eds.), Encouraging reflective practice in education: An analysis of issues and programs (pp. 97-118). New York: Teachers College Press.

Seidel, J. (2006). Some thoughts on teaching as contemplative practice. Teachers College Record, 108, 1901-1914. <http://www.tcrecord.org> ID Number: 12687, Date Accessed: 10/26/2007 3:58:14 PM. 
Shulman, L.S. (2004). Teaching as community property: Essays on higher education. San Francisco: Jossey-Bass.

Shulman, L.S. (2004). The wisdom of practice: Essays on teaching, learning, and learning to teach. San Francisco: Jossey-Bass.

Spalding, E., and Wilson, A. (2002). Demystifying reflection: A study of pedagogical strategies that encourage reflective journal writing. Teachers College Record. <http://www.tcrecord.org>104.7. 1393-1421.

Tomlinson, C. (2001). How to differentiate instruction in mixed-ability classrooms. Alexandria, VA: Association for Supervision and Curriculum Development.

Wiggins, G. and McTighe, J. (2001). Understanding by design. Upper Saddle River, NJ: Prentice Hall.

Zajonc. A. (2005). Love and knowledge: Recovering the heart of learning through contemplation. Teachers College Record. Volume 108 Number 9, 2006, p. 1742-1759 <http://www.tcrecord.org> ID Number: 12678, Date Accessed: 10/26/2007 4:11:01 PM.

\section{Appendix A}

(You can close your eyes to imagine this if you want.) You stand before a mirror. Project a rose onto the mirror and look at it for a few moments. Now change the rose to a purple one. Then change the rose to a yellow one.

Now....You see yourself. You see yourself as a writer.

For the next 20 minutes write about this reflection that you see.

Write about....

Your accomplishments so far in writing.

Your failures.

\section{Writing Prompt 1: Writing from the Inside}

Yourself as writer with music, with images, with people, with food, traveling.

Yourself as a writer politik (in the world of politics).

The biggest challenges you face as a writer

Being alive in 2007 as a writer.

Write about what you think and feel about writing...and how YOU fit into your life this semester (these past years, the rest of your life).

\section{Appendix B}

\section{Writing Prompt 2: Writing from the Outside}

If you saw Baraka.....

Write about the film you just saw. Write about an image, many images, how you feel afterwards. 
If you were unable to see the film, choose from the collection of images, one image, several images, all the images.... and write a story, a description, a reflection. 